results published. Sanatorium treatment properly conducted still holds the premier place in the treatment of tuberculosis, and excellent results can be obtained in the majority of carly cases and in a proportion of advanced cases.

I am, Sir, yours faithfully,

J. M. JoHNston, M.B., D.P.H.

Tor-na-Dee Sanatorium, IInrtle. Aberdecnshire, May 26 th, 1921 .

\section{WARMING ETHER VAPOUR FOR INHALATION.}

To the Editor of THE IAAxceT.

SIR,--Dr. K. B. Pinson drew attention last week to the danger of heating ether-laden air by an electric incandescent lamp. and in connexion with this has referred to an intratracheal ether apparatus described by men in your issue of April 2nd. While designing this apparatus I had in mind the accident described by Dr. W. J. MeCardie. and have done everything possible to eliminate the risk of such an occurrence. The apparatus when properly connected is vapourtight, the only place from which the vapour can escape, with the exception of the tube leading to the patient, is through the mercury safety ralve, which is adjustable. A manometer is attached to the apparatus. By means of this the pressure at which the vapour is being delivered can easily be seen ; the safety valve is therefore only a means of rendering it impossible to raise the pressure above the desired maximum.

In practice one finds that it is quite unnecessary to cause the safetr valve to blow off. Furthermore, the length of rubber tubing that I adrocate for use between the apparatus and the patient is at least six feet, therefore it is possible to have the apparatus a considerable distance from the patient. I have proved, by putting a thermometer in the current of rapour issuing from this tube, that by adjusting the heater it is possible to maintain a rapour at any desirable constant temperature. In my opinion it is practically impossible for any fire or explosion to take place even if the connexions are faulty.

Dr. Pinson's suggestion of warming the vapoux by passing it through a length of rubber tubing placed on the patient's chest would. I think. greatly add to the risk of getting the tube pinched, and, in a number of cases for which intratracheal anæsthesia is used, the tube would impede the surgeon's work.

$$
\text { I am, Sir, yours faithfully, }
$$

A. W

London, W., May 30th, 1921 .

$$
\text { A. W. MATTHEW, }
$$

THE INTERNECTNE TENEREAL CAMPAIGN. To the Editor of THE LANCET.

SIR,-A writer in your columns (May 21st), signing himself "Morphologist," criticises a recent article of mine in the Morning Post, and appears to challenge my right as a layman to express any opinion on current controversies with regard to venereal disease. I have the greatest respect for the opinion of competent experts on subjects exclusively covered by expert knowledge. But the controversial issues with regard to venereal disease are not matters for expert pronouncement. They depend on ethical quite as much as on medical considerations. Indeed, the only medical issue that arises is whether treatment before connexion is more likely to prevent infection than treatment several hours after infection. On this point your correspondent, who says that his name proves that he ought to know his subject, is silent. He confines his argument to points on which his expert knowledge gives him no right to claim papal infallibility.

The issue between the two societies, the S.P.V.D. and the N.C.C.V.D., is very simple. Both accept the fairly obvious proposition that-to quote your correspondent's words-the "fundamental cause of venereal disease is the indulgence in promiscuous sexual intercourse" ; both appeal to everybody to refrain from this indulgence; but both recognise that some people will not refrain. Up to this point the two societies have identically the same policy; the divergence then arises. To those men who will not refrain, the S.P.V.D. says: "Take certain precautions in advance"; the N.C.C.V.D. savs: "Wait till you have had' connexion and then report yourself as quickly as you conveniently can to some public institution where you will receive treatment at the public expense." Since your well-informed correspondent is silent on the relative medical merits of these two plans, I think I am entitled to assume that the former plan is more likely to prevent infection. That being so, I contend, as I argued in the Morning Post, that the Ministry of Health is not justified in spending public money in giving effect to the latter plan or in advertising the society that adrocates that plan.

Ethically there is no distinction between the two courses. If it is ethically wrong to tell a man how he can help himself to sin in safety, it must also be ethically wrong to set up public institutions to give him a chance of escape after he has sinned. Possibly Dr. Addison and Sir Alfred Mond and the other theologians who direct the policy of the Ministry of Health may argue that their policy is less sinful because it provides less safety. But if they use that argument they confess themselves guilty of hypocrisy in pretending that the purpose of the Ministry is the promotion of the national health.

I am, Sir, yours faithfully,

Gray": Inn. May" 24th, 1921. HARoLd Cox.

\section{To the Editor of THE LANCET.}

SIR.-In his letter to you in THE LANCET of May 21st " Morphologist," attacking Mr. Harold Cox for his support of the movement for the medical prevention of venereal disease, betrays even more ignorance of the subject than that which he attributes to Mr. Cox. I adduce the following comments in justification of this proposition.

1. "Morphologist's" statement that the Society for the Prevention of Tenereal Disease recognises the importance of the ethical factor is quite correct; but his further statement that Mr. Cox " fails as a critic" by not mentioning this fact is based on a misconception. The S.P.Y.D., while recognising fully the obvious fact that renereal diseases would necessarily be reduced to a minimum, or nearly die out, if promiscuous sexual intercourse could be wholly stayed by ethical or religious teaching, came into existence solely because the Royal Commission on Venereal Disease, the National Council for Combating Venereal Diseases, and the Ministry of Health, which has all along supported the recommendations of these bodies; had completely ignored the element of immediate self-disinfection as an essential part of any practical measure for compassing a material reduction of venereal diseases. It is clear that Mr. Cox was aware of this fact, and was in no sense unfair to the S.P.I.D. by omitting to insist on the obvious.

2. "Morphologist" does not seem to know that venereal disease is strictly contagious, and can be directly prevented by personal disinfection; that disinfection is effectual in proportion to the quickness of its application; and that the N.C.C.V.D. advise the use of soap and water, which, being practically unportable, are therefore unavailable in the majority of cases. Neither does he seem to realise that, apart from soap and water, the N.C.C.'s recommendations are-moral injunctions, which have demonstrably failed as a means of prevention-and the treatment of those already infected, which never lessens the incidence of any disease. Yet surely even a "learned layman" ought to know that appropriate sanitation is the universally recognised method for diminishing the incidence of all diseases. 